\title{
Sintesis dan Karakterisasi Membran Kitosan/LiOH sebagai Elektrolit Padat Baterai Sekunder
}

\author{
Sunardi $^{1{ }^{1 *},}$, Aris Haryadi ${ }^{1}$, Wihantoro ${ }^{1}$, Evi Yulianti ${ }^{2}$ \\ ${ }^{1}$ Jurusan Fisika FMIPA Universitas Jenderal Soedirman \\ ${ }^{2}$ PSTBM Batan Tenaga Atom Nasional Serpong Indonesia \\ *e-mail corresponding author: sunardi.unsoed@gmail.com
}

\begin{abstract}
Abstrak - Sintesis dan karakterisasi membran Kitosan/LiOH dilakukan bertujuan untuk menentukan pengaruh PVA/LiOH terhadap mikrostruktur membran elektrolit padat baterai sekunder. Sintesi membran Kitosan/LiOH dilakukan dengan metode casting dengan variasi konsentrasi w/w LiOH. Karakterisasi dilakukan menggunakan FTIR (Fourier Transform Infra Red) dan SEM (Scanning Electron Microscopy). Hasil FTIR membran kitosan/LiOH menunjukkan adanya interaksi antara kitosan/LiOH. Pada panjang gelombang $3500 \mathrm{~nm}$ terbentuk gugus fungsi $-\mathrm{OH}$ baru dan pada $1500-945 \mathrm{~nm}$ terbentuk ikatan bending antara gugus fungsi $-\mathrm{OH}$ dengan NH3. Hasil SEM menunjukkan terbentuk agglomerasi dengan bertambahnya konsentrasi LiOH pada larutan. Terjadi distribusi partikel homogen di permukaan membran. Hal ini menunjukkan bahwa adanya pengaruh penambahan LiOH pada pembentukan membran yang menghasilkan ikatan antar atom yang semakin renggang/tidak stabil dan bahan yang semakin konduktif..
\end{abstract}

Kata kunci: Gugus fungsi, ukuran butiran, kitosan, $\mathrm{LiOH}$, elektrolit

\begin{abstract}
The synthesis and characterization of chitosan/LiOH membranes was carried out aimed to determine the effect of chitosan/LiOH on the electrolyte membrane microstructure of secondary batteries. Synthesis of chitosan/LiOH membranes was carried out by casting method with concentration variations $w / w \mathrm{LiOH}$. The characterization was carried out using FTIR (Fourier Transform Infra Red) and SEM (Scanning Electron Microscopy). The results FTIR of chitosan/LiOH membrane showed an interaction between chitosan/LiOH. At a wavelength of $3500 \mathrm{~nm}$ a new -OH functional group is formed and at 1500-945 nm a bending bond is formed between the -OH group and $-\mathrm{NH}$. The SEM results show that agglomeration is formed by increasing the concentration of LiOH in the solution. A distribution of homogeneous particles occurs on the surface of the membrane. This shows that there is the effect of adding LiOH to the formation of membranes which results in increasingly tenuous / unstable atomic bonds and increasingly conductive materials.
\end{abstract}

Key words: Functional group, grain size, chitosan, $\mathrm{LiOH}$, electrolyte

\section{PENDAHULUAN}

Kitosan $\left[\mathrm{C}_{6} \mathrm{H}_{11} \mathrm{NO}_{4}\right]_{\mathrm{n}}$ adalah biopolimer organik, yang memiliki sifat-sifat non-toksik, biokompatibel, biodegradable, dan hidrofilik. Kitosan berasal dari cangkang hewan seperti kepiting, udang dan lobster. Kitosan terdiri dari amina dan hidroksil [1,2]

Membran adalah daerah tipis antara dua fase yang memberikan lintasan tertentu ${ }^{[3-6]}$, sehingga memungkinkan fase atau komponen tertentu menembus lebih cepat dibandingkan dengan fase atau komponen lainnya di bawah pengaruh gaya penggerak (driving force) [7,8]. Membran polimer elektrolit padat (solid electrolyte polimer membrane) (SPE) dalam penelitian ini dihasilkan oleh kitosan/LiOH.

Membran elektrolit padat memiliki potensi yang besar untuk diaplikasikan dalam berbagai bentuk peralatan elektronik dengan berbagai kelebihan yaitu tahan terhadap kebocoran, panas dan memiliki kestabilan terhadap getaran dan benturan. Sintesis membran kitosan/LiOH dilakukan untuk menghasilkan elektrolit padat dalam sebagai filler baterai sekunder. Sedangkan, pengujian morfologi sampel menggunakan SEM dan gugus fungsi menggunakan FTIR.

\section{METODE}

\section{A. Bahan dan alat}

Bahan-bahan yang digunakan dalam penelitian ini adalah kitosan, asam asetat (Merck), PVA dan LiOH (Sigma-Aldrich). Sedangkan alat yang digunakan adalah neraca Ohauss Galaxy TM 160, mikrometer skrup, desikator, cawan petri dan gelas ukur. 


\section{B. Prosedur}

Sintesis membran kitosan dilakukan dengan cara 3 gram kitosan dilarutkan ke dalam $100 \mathrm{~mL}$ asam asetat sambil diaduk dengan menggunakan magnetic stirrer sehingga membentuk larutan homogen. Selanjutnya 3 gram PVA dicampur ke dalam larutan kitosan dan diaduk selama 3 jam. Setelah homogen dimasukkan $\mathrm{LiOH}$ dengan konsentrasi 3\% dan 5\%. Kemudian dicetak ke dalam cawan petri dan dikeringkan pada suhu $60{ }^{\circ} \mathrm{C}$ selama 2 hari. Membran yang sudah kering, siap dilakukan pengujian.

\section{Karakterisasi membran kitosan/LiOH}

Spektra FTIR membran kitosan/LiOH diperoleh dengan menggunakan Shimadzu 8201 PC FTIR spektrofotometer dan direkam dengan resolusi $1 \mathrm{~cm}^{-1}$ dengan rentang bilangan gelombang dari 400 hingga $4000 \mathrm{~cm}^{-1}$ untuk menentukan gugus fungsi. Struktur mikro dan distribusi grain size menggunakan Scanning Electron Microscopy (SEM) tipe JEOL, JSM6510LA dengan pembesaran 1000x pada suhu kamar. Sampel dilapisi dengan emas selama 100 detik, dengan arus listrik $I=60 \mathrm{~mA}$. Prosedur ini dilakukan untuk mendapatkan kualitas gambar yang lebih baik.

\section{HASIL DAN PEMBAHASAN}

\section{A. Uji SEM}

Hasil SEM pada membran kitosan, kitosan/PVA dan kitosan/PVA/LiOH dapat dilihat pada Gambar 1 (a), (b) dan Gambar 2. Dari struktur morfologi permukaan membran yang dihasilkan tampak mulus dan terdiri dari butiran yang homogen yang menyebar merata di seluruh permukaan. Tidak terjadi agglomerasi serta cenderung berpori. Setelah dilakukan pengujian dengan SEM maka hasil SEM menggambarkan bahwa terjadi aggolmerasi antara molekul-molekul penyusun kitosan, PVA dan LiOH. Semakin tinggi konsentrasi $\mathrm{LiOH}$ digunakan semakin banyak ion-ion pembawa muatan bebas bisa bergerak bebas.

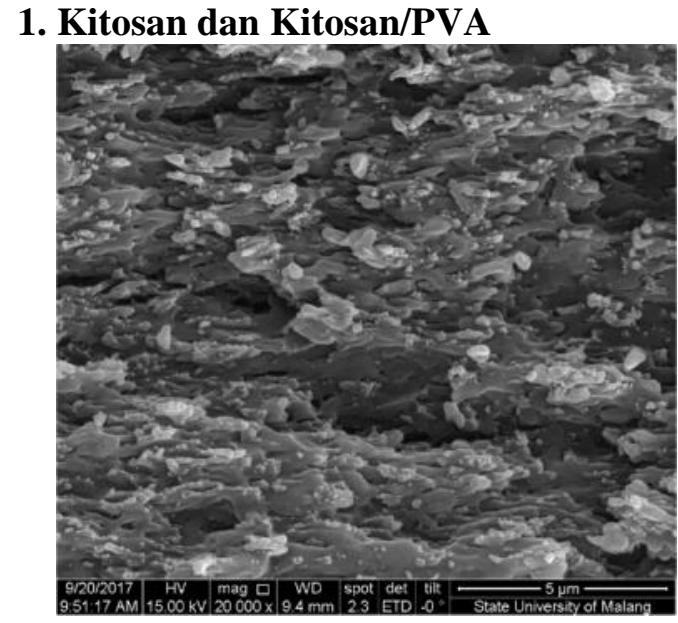

(a)

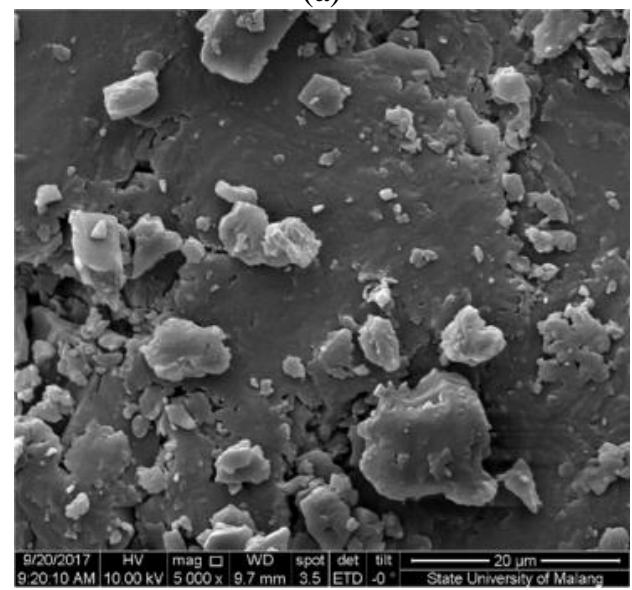

(b)

Gambar 1. Hasil SEM (a) Kitosan , (b) Kitosan/PVA

\section{Kitosan/PVA/LiOH}

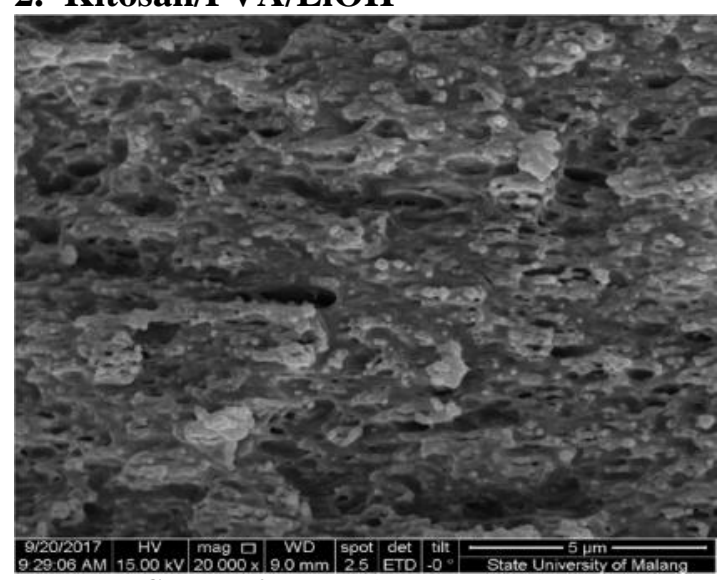

Gambar 2. SEM Kitosan/PVA/LiOH

Hasil SEM menunjukkan bahwa semakin besar konsentrasi yang ditambahkan pada membran akan menghasilkan ikatan antar atom yang semakin renggang/ tidak stabil dan menghasilkan bahan yang semakin konduktif. 


\section{B. Uji FTIR}

\section{Kitosan dan PVA}

Hasil FTIR dari kitosan murni dan PVA dapat dilihat pada Gambar 3 (a) dan (b). Pada Gambar 1 (a) dan (b), daerah serapan terjadi pada bilangan gelombang 2000 $1000 \mathrm{~cm}^{-1}$. Daerah serapan juga terjadi pada bilangan gelombang $1700,89 \mathrm{~cm}^{-1}$ yang menunjukkan gugus fungsi $\mathrm{C}=\mathrm{O}$ asimetri dan pada $1429,65 \mathrm{~cm}^{-1}$ terjadi gugus fungsi $\mathrm{C}=\mathrm{O}$ simetri dari kitosan. Daerah bilangan gelombang 2300,76 $\mathrm{cm}^{-1}$ gugus fungsi $\mathrm{C}-\mathrm{OH}$ bending. Daerah bilangan gelombang $1650,78-600 \mathrm{~cm}^{-1}$ menunjukkan gugus fungsi $\mathrm{C}=\mathrm{O}$, sedangkan daerah bilangan gelombang 3000 - 2500 $\mathrm{cm}^{-1}$ terbentuk gugus $\mathrm{C}-\mathrm{H}$ bending. Pada puncak $3500 \mathrm{~cm}^{-1}$ terbentuk gugus fungsi O$\mathrm{H}$ bending.

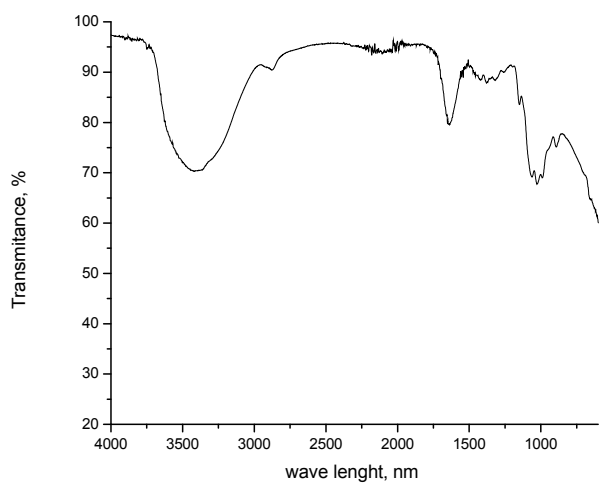

(a)

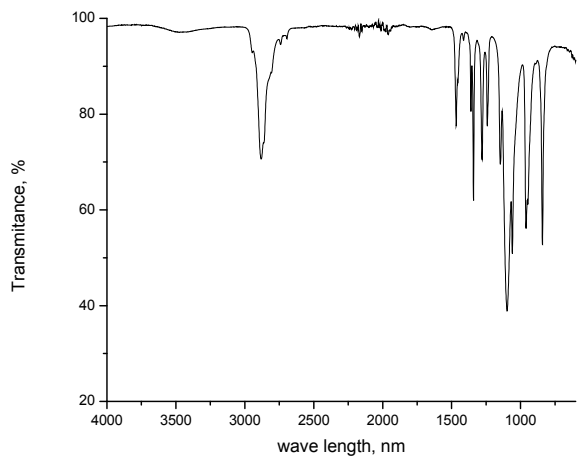

(b)

Gambar 3. (a) Spektrum FTIR Kitosan, (b) FTIR Kitosan/PVA

\section{Kitosan/PVA dan Kitosan/PVA/LiOH}

Gambar 4.(a) dan (b). menunjukkan adanya interaksi antara kitosan dengan PVA dan $\mathrm{LiOH}$ yang kuat sehingga terbentuknya gugus fungsi yang baru. Pada bilangan gelombang $3000-$ $2750 \mathrm{~cm}^{-1}$ terbentuk puncak baru yang menunjukan gugus fungsi $\mathrm{C}-\mathrm{H}$ bending dengan $-\mathrm{CH}_{2}$ dan $-\mathrm{CH}_{3}$. Pita serapan terjadi pada bilangan gelombang $1750,87-1475,45 \mathrm{~cm}^{-1}$ terbentuk gugus $\mathrm{NH}_{2}$ bending. Dari hasil ketiga spektra IR tersebut menunjukkan adanya pergeseran, kenaikan, penurunan intensitas, dan terbentuknya gugus baru pada membran kitosan/PVA/LiOH.

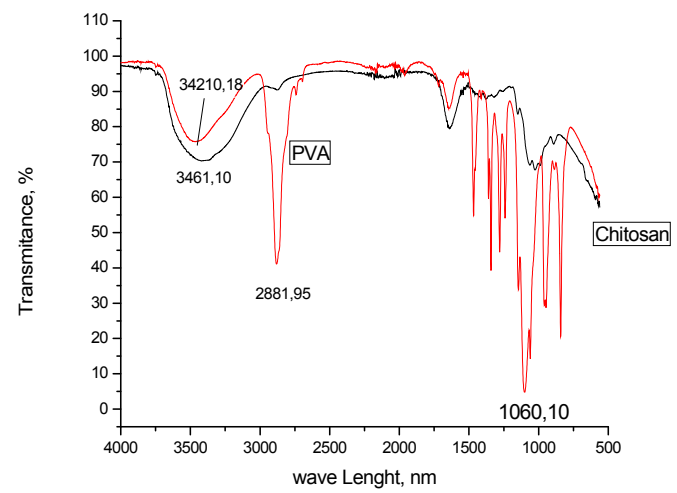

(a)

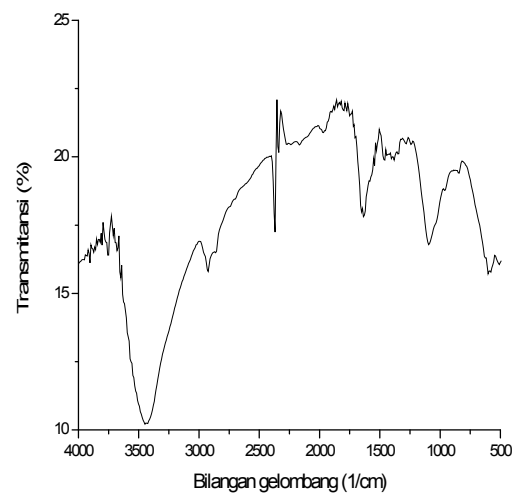

(b)

Gambar 4. (a) FTIR Kitosan-PVA, (b) FTIR Kitosan/ $\mathrm{PVA} / \mathrm{LiOH}$

Terlihat bahwa pada spektrum FTIR kitosan/PVA/LiOH pada panjang gelombang 1550 - $544 \mathrm{~nm}$ terjadi bending antara $-\mathrm{OH}$ dan $-\mathrm{NH}_{3}$. Bending dan stretching terjadi akibat adanya pola teratur 
dan dominan antara molekul pembentuk kitosan dan PVA.

\section{Uji XRD}

Hasil XRD pada membran kitosan, kitosan/PVA dan kitosan/PVA/LiOH dapat dilihat pada Gambar 5.

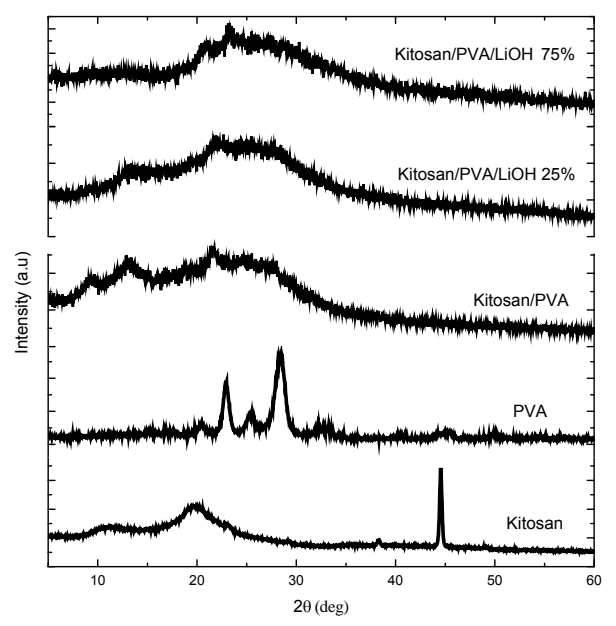

Gambar 5. Hasil XRD membran kitosan, kitosan/PVA dan kitosan/PVA/LiOH

Hasil XRD membran kitosan, kitosan/PVA dan kitosan/PVA/LiOH menunjukkan bahwa semakin besar konsentrasi $\mathrm{LiOH}$ yang digunakan, menghasilkan intensitas membran menurun dan bahan akan semakin bersifat amorf. Hal ini menunjukkan bahwa partikelpartikel pada kisi kristal akan berpindah posisi sehingga membuat kekosongan pada kisi kristal.

\section{KESIMPULAN}

Dari penelitian yang telah dilakukan dapat diambil kesimpulan bahwa terjadi pembentukan gugus fungsi baru $-\mathrm{OH}$ pada kitosan/ $\mathrm{LiOH}$ pada panjang gelombang $3500 \mathrm{~nm}$ dan terjadi interasi ikatan bending antara $-\mathrm{OH}$ dan $\mathrm{NH}_{3}$ pada panjang gelombang $1500-945 \mathrm{~nm}$. Kitosan/LiOH menghasilkan membran lebih fleksibel dan tidak bersifat higroskopis. Kitosan/LiOH dapat digunakan sebagai bahan alternatif elektrolit padat baterai sekunder

\section{UCAPAN TERIMA KASIH}

Terima kasih kepada Kementrian Ristek dan Dikti melalui Universitas Jenderal Soedirman melalui Riset Peningkatan Kompetensi Tahun 2018.

\section{DAFTAR PUSTAKA}

[1] O. G. Abdullah, R. R. Hanna, and Y. A. K. Salman, "Structural, optical, and electrical characterization of chitosan: methylcellulose polymer blends based film," J. Mater. Sci. Mater. Electron., vol. 28, no. 14, pp. 10283-10294, 2017.

[2] A. Badawi, E. M. Ahmed, N. Y. Mostafa, F. Abdel-Wahab, and S. E. Alomairy, "Enhancement of the optical and mechanical properties of chitosan using $\mathrm{Fe}_{2} \mathrm{O}_{3}$ nanoparticles," J. Mater. Sci. Mater. Electron., vol. 28, no. 15, pp. $10877-$ 10884, 2017.

[3] M. Barchuk et al., "Structure and surface properties of chitosan/PEO/gelatin nanofibrous membrane," J. Polym. Res., vol. 23, no. 2, pp. 1-7, 2016.

[4] W. Zhang, J. Zhang, and W. Xia, "Effect of ball-milling treatment on physicochemical and structural properties of chitosan," Int. J. Food Prop., vol. 17, no. 1, pp. 26-37, 2014.

[5] Rochima, E., Azhary, S.Y., Prata, R.I., Panatarani, C., and Joni, I.M. Preparation and characterization of nano chitosan from crab shell waste by beads milling method. International conference on Food Science and Engineering. (2016) 193. http://doi.org/10.1088/1757899X/193/1/012043.

[6] Liu, T.Y., Ma, Y., Yu, S.F., Shi, J., and Xue, S. The effect of ball milling treatment on structure and porosity of maize starch granule. Innovative Food Science and Emerging Technologies, (2011) 586-593. http://doi.org/10.1016/j.ifset.2011.06.009.

[7] Zhan, W., Zhang, J., and Xia, W. Effect of ball milling treatment on physicochemical and structural properties of chitosan. International Journal of Food Properties, (2014) 26-37.

http://doi.org/10.1080/10942912.2011.6081 $\underline{75}$.

[8] Ker, W.L., Ward, SDW., McWatters, KH., and Resurreccion, AVA. Effect of milling and particle size on functionality and physicochemical properties of cowpea flour. American Association of Cereal Chemists Inc. Publication no. C-20000212-02R. (2000). 